hospitals, each with general psychiatric units, and one psychiatric hospital within the city limits. Only one of those general hospitals has any formal limited psychogeriatric funding. Particularly in the case of those patients who are 'not wanted by other services', frequently their needs are not met at all. Our own District Health Council, under pressure from the Ontario Ministry of Health, is now at long last looking at the need to develop co-ordinated services in geriatric psychiatry as the only way to ensure adequate access based on the needs of the community.

In the ideal psychogeriatric model, most new patients would be seen in domiciliary consultation (DC). In the ideal model more than one discipline may need to be involved at a DC level, especially when the patient is not going to be admitted to hospital. Where the psychogeriatrician and nurse or social worker work closely together, the patient can only benefit. Some, but not all patients, may benefit from assessment by one discipline alone.

DAVID J. HARRIS, University of Western Ontario, Victoria Hospital, London, Ontarlo, Canada N6A 4 G5

\section{The reorganised mental health service}

Sir: Although now retired, I very much enjoy the articles in the Bulletin, with their emphasis on the practical problems facing those working in the now reorganised mental health service. In your April 1994 issue, you have two articles on how the operation of the internal market is likely to effect the functioning of such a service.

I was, however, taken aback by one paragraph in Gregory Richardson's article 'Psychiatry: a contracting specialty' (Psychiatric Bulletin, April 1994, 18, 200-202). Under 'Action required' he mentions the need:

"to clarify and separate the many different aspects of the psychiatrists' work-loads so that costs can be allocated appropriately; for example, by clarifying the percentage of time spent in general psychiatry and how much with each special interest, and then further by breakdown into time spent on in-patient and out-patient work, then dividing that by the in-patients and out-patients, in order to calculate costs per case. Follow-up appointments, letter writing, attendance at case conferences etc must all be included to ensure costs are accurately calculated ... Travelling time and consultation work may have to be priced separately and added to outpatient costs of individual patients".

After this breathtaking foray into health economics, can I suggest to Dr Richardson that he also includes time spent on thinking and worrying about some patients in his costing exercise. And what about charging a little more for those we treat with some empathy and even more when combined with warmth and genuineness.

I want to be fair to Dr Richardson. The internal market has created serious problems for the financing of a good psychiatric service and his article is meant as a constructive contribution to solving the complex difficulties involved. It is his acceptance of the principles of the internal market which has resulted in the nonsense he has written in the paragraph quoted.

BENJAMIN STEINBERG, Emeritus Consultant Psychiatrist, Southampton and SW Hants District Health Authority

Sir: Dr Steinberg has had the good fortune to retire from the rigours of the market economy in the National Health Service. We not face an era in which consultants' time and money must be clearly accounted for or it will not be paid for by purchasers. We can only do this if we clarify what our work involves in its many aspects which include follow-up appointments, letter writing, attendance at case conferences, consultation work and travelling time. For as the contracting system becomes steadily more sophisticated we will have to account for our expenses on each individual case; after all when we go to Marks \& Spencers we buy things individually, not by department.

Consultants receive a reasonable salary which I am sure is a baseline to acknowledge that dealing with patients with empathy, warmth and genuineness is a basic requirement for the job.

I don't have to like this system, but I have to work in it if I'm going to get the best for my patients.

G.J.R. RICHARDSON, Lime Trees Child, Adolescent and Family Unit, 31 Shipton Road, York YO3 6RE

\section{Psychiatric training and the European Union}

Sir: Although Jan Neeleman \& Jim van Os (Psychiatric Bulletin, April 1994, 18, 193-195) provide an interesting comparative study of psychiatric training in Europe, their conclusions do not accord with the facts.

Their general thesis is that the changes to training required under European Union Medical Directives will mean the end of training and psychiatry as we know it in the UK. Existing subspecialities will disappear and psychiatric research will suffer.

Meeting the EU directives simply means that any specialist within the EU has the right to practise his or her speciality in Britain. 